\section{Discurso médico e práticas alimentares no Hospital Real de Moçambique no início do século XIX}

\section{Medical discourse and eating habits in the Hospital Real de Moçambique in the early nineteenth century}

RODRIGUES, Eugénia. Discurso médico e práticas alimentares no Hospital Real de Moçambique no início do século XIX. História, Ciências, Saúde - Manguinhos, Rio de Janeiro, v.21, n.2, abr.-jun. 2014, p.609-627.

\section{Resumo}

Com base em estudos e documentos de arquivo, explora-se o modo como as práticas médicas europeias que relacionavam dieta e saúde, no início do século XIX, foram transpostas para África, especificamente Moçambique. Examina-se a evolução das teorias europeias sobre o papel preventivo e terapêutico da alimentação, destacandose as concepções da medicina humoral e a sua reconfiguração pela ciência iluminista. Descreve-se o hospital moçambicano, considerando as categorias de doentes assistidos e as doenças prevalecentes na região. Focam-se as alterações introduzidas na alimentação hospitalar, aproximando-a da europeia. Analisam-se essas modificações em articulação com os desenvolvimentos do discurso médico europeu, reconstruído pela fisiologia e pela química, em torno do corpo e dos alimentos.

Palavras-chave: discurso médico; dieta hospitalar; humoralismo; solidismo; Moçambique.

Abstract

Based on studies and archive documents, this work investigates the way European medical practice that interrelated diet and health in the early nineteenth century was transported to Africa, specifically Mozambique. The development of European theories about the preventive and therapeutic role of diet is examined, highlighting the conceptions of humoral theory and its reconfiguration by the science of the Enlightenment. The Mozambican hospital is described, taking into account the categories of patients cared for and prevailing diseases in the region. Focus is given to the changes introduced to hospital food to bring it closer to European habits. These changes are analyzed in the light of developments in European medical discourse about the body and foodstuffs, reconstructed by physiology and chemistry.

Keywords: medical discourse; hospital diet; humoralism; solidism; Mozambique.
Recebido para publicação em janeiro de 2013.

Aprovado para publicação em novembro de 2013.

http://dx.doi.org/10.1590/S0104-59702014000200009 
$\mathrm{O}$ s estudos sobre a história da medicina evidenciaram como as teorias médicas europeias formularam uma articulação íntima entre saúde e alimentação. Essa associação foi firmemente instituída pela medicina humoral hipocrático-galénica e, com variações temporais, influenciou fortemente as concepções sobre a relação entre os alimentos e a saúde na Europa até Oitocentos. Incluída entre os agentes externos que podiam afectar o equilíbrio do corpo, a comida foi medicamente interpretada e socialmente percepcionada como fonte de saúde ou de doença (Estes, 2000; Lindemann, 2010; Flandrin, Montanari, 2001).

No período moderno, como argumentou Jean-Louis Flandrin (2001c), a emergência do gosto implicou um afrouxamento da representação social do valor preservativo e terapêutico da comida, tal como ele fora visto pela medicina humoral. No entanto, como vários estudos mostraram, o vínculo entre dieta e saúde não foi elidido do discurso médico e das vulgatas que o difundiam junto ao público, porquanto os desenvolvimentos da ciência iluminista, nomeadamente da fisiologia e da química, abriram novos questionamentos sobre a relevância dos modos de comer na conservação da saúde e na sua recuperação (Estes, 2000; Smith, 2002; Shapin, 2003; Spary, 2012).

Essas concepções foram transplantadas para os territórios dos impérios europeus, onde, não raro, tiveram de se acomodar e negociar com os entendimentos locais sobre essa questão, bem como com o funcionamento dos mercados. No caso do espaço imperial português, são poucos os estudos que exploram os modos de alimentar os enfermos em articulação com as abordagens médicas. Este artigo visa, precisamente, analisar a transposição para Moçambique do discurso médico europeu sobre a alimentação e como ele interagiu com os padrões dietéticos construídos no hospital da Ilha de Moçambique. Pretende-se discutir o modo como as alterações do discurso médico se ajustaram ao meio tropical e como novas perspectivas sobre a dieta dos enfermos afectaram as práticas alimentares no hospital, nas primeiras décadas do século XIX. A fim de entender essa dinâmica, este artigo baseia-se na análise de textos de médicos que actuaram em Moçambique e em fontes qualitativas e quantitativas sobre a alimentação no Real Hospital, como ementas, listas de compras e registos das refeições.

Na primeira parte do texto, examina-se a evolução das perspectivas europeias sobre o papel preventivo e terapêutico da alimentação. Evidencia-se como as novas ideias sobre a fisiologia e a química dos alimentos, no período moderno, reconfiguraram a narrativa sobre a dieta, apesar da persistência das concepções humorais. De seguida, faz-se uma breve caracterização do Real Hospital de Moçambique, considerando os seus doentes e as doenças aí prevalecentes. Na terceira parte, exploram-se as alterações na dieta hospitalar introduzidas pelos físicos-mores europeus, em articulação com as ementas dos hospitais da Europa. Finalmente, discute-se o modo como essas mudanças alimentares se relacionaram com o discurso médico europeu, interpretado por físicos-mores que actuaram no hospital moçambicano. Importa notar que, a par da comida, as bebidas, que, por economia de espaço, não serão tidas em conta aqui, também eram olhadas medicamente.

\section{A alimentação no discurso médico europeu: persistências e mudanças}

Durante longo tempo, a interpretação da doença na Europa baseou-se na teoria humoral, que, com raízes anteriores, foi desenvolvida por Hipócrates (460-370 a.C.) e sistematizada 
por Galeno (129-c.199). A fisiologia humoral explicava o funcionamento do corpo com base no equilíbrio de quatro humores ou fluidos corporais: sangue, linfa (pituíta, fleuma), bílis amarela e bílis negra (atrabílis). Os humores eram reportados aos quatro elementos - ar, água, fogo e terra - e associados a outras tantas qualidades: seco, húmido, quente e frio. A mistura desses fluidos, com configurações pessoais irrepetíveis, era entendida como originando o temperamento individual, classificado como sanguíneo, fleumático, colérico ou melancólico, denominação que derivava do humor considerado predominante numa pessoa. A par do temperamento, também era concedida relevância à constituição corporal do sujeito, a qual podia predispô-lo para a doença. A constituição era percebida como algo mais do que o conjunto das partes do corpo, dos humores e do modo de vida, e traduzida na qualificação dos indivíduos como robustos, delicados, fortes e fracos. Os conceitos de temperamento e de constituição escoravam a ideia da natureza individual da doença, que sobrevinha quando os fluidos entravam em desequilíbrio (Lindemann, 2010, p.11-24). A teoria humoral configurou a medicina europeia durante séculos e, concedendo um lugar destacado ao regime de vida na saúde dos indivíduos, influenciou as perspectivas sobre a alimentação.

Com efeito, já antes de Hipócrates, os filósofos reconheciam à alimentação um papel na conservação da saúde. Mas parece terem sido os textos desse médico e dos seus discípulos a enfatizarem o uso preventivo e terapêutico da comida. Em particular, nos Aforismos, o médico descreveu as dietas recomendadas em função de distintas doenças. Mais tarde, os físicos helenísticos argumentaram que os alimentos eram mais importantes para a cura das doenças do que os próprios remédios. Galeno defendeu mesmo que as enfermidades eram causadas por erros do regime de vida, incluindo a dieta, pelo que podiam ser acauteladas. ${ }^{1}$ De facto, a teoria humoral considerava que os alimentos interferiam nos fluidos, consoante a sua capacidade de tornar o corpo quente, frio, seco e húmido, bem como entendia que eles influenciavam o processo de digestão, que podia, ele próprio, afectar esses humores. Como salientou J. Worth Estes (2000, p.1535-1536), na medicina humoral, a comida, assim como os remédios com os quais se confundia, era prescrita para corrigir os desequilíbrios dos humores e modificar o processo digestivo.

Essas ideias foram transmitidas à Europa medieval através dos escritos de autores árabes, que tinham igualmente integrado as tradições médicas indianas, elas próprias concedendo, também, um lugar aos humores na explicação da saúde e da doença (Arnold, 2004, p.66; Arnold, 2013). A tradução latina dos tratados árabes, a partir do século XII, permitiu que esses autores fossem estudados na Europa. O Cânon de Medicina, de Avicena (980-1037), foi uma das obras mais influentes. Avicena distinguia as propriedades medicinais da comida do seu valor nutricional, classificando-a como sendo de qualidade rica ou pobre, leve ou pesada, saudável ou nociva, e incluía regras dietéticas aplicáveis a indivíduos saudáveis e aos doentes (Estes, 2000, p.1536; Lindemann, 2010, p.86-90; Cook, 2008, p.410). As ideias hipocráticogalénicas tiveram uma circulação mais intensa depois da chegada à Europa dos médicos fugidos de Constantinopla, tomada pelos turcos em 1453, os quais traduziram os escritos clássicos directamente do grego. Multiplicaram-se os livros sobre higiene alimentar que interpretavam os usos médicos dos alimentos (Castro, 2011, p.74-81; Estes, 2000, p.1537; Smith, 2002).

Reconfiguradas em interacção com novas teorias médicas, as ideias hipocrático-galénicas sobre a alimentação continuaram extraordinariamente actuantes. No século XVIII, os cursos 
de medicina incluíam o ensino da dietética, um conjunto de normas que regulava a relação do indivíduo com o meio, expressa nos não naturais, um conceito derivado de Galeno, mas formulado no período medieval. Os não naturais reportavam-se aos agentes externos capazes de agir sobre o corpo e causar doenças. Incluíam-se aí a alimentação e a bebida, cujas qualidades (quente, frio, seco, húmido) tinham de concordar com o temperamento do indivíduo para que ele mantivesse a saúde ${ }^{2}$ (Broman, 2003, p.466-467; Cook, 2008, p.410; Lindemann, 2010, p.13-16, 88-89; Beatty, 2012, p.101). Nesse quadro, a culinária desempenhava um papel importante, corrigindo as características dos alimentos e tornando-os digeríveis, através do modo de cozinhar e da adição de temperos, como especiarias (Flandrin, 2001a, p.157-158). Conforme sublinhou Georges Vigarello (2012, p.127), o saber desse período aprofundava "convicções antigas, detalhando princípios inalterados".

Todavia, em Setecentos, as teorias fisiológicas derivadas da química e da mecânica competiam com a fisiologia humoral, abrindo novas perspectivas sobre a relação entre os alimentos e a saúde. A apropriação da mecânica e da química pela medicina e, bem assim, a sua contestação organizaram-se em torno de várias correntes, mas, em todas elas, conformavase a ideia de que a doença não decorria apenas da desarmonia dos humores, residindo também no tónus, ou seja, na força e na elasticidade dos componentes sólidos do corpo. Os médicos Hermann Boerhaave (1668-1738), oriundo da iatromecânica, que perspectivava o corpo como uma máquina, e Georg Ernst Stahl (1659-1734), que valorizava a “anima', a alma, responsável pela oposição do corpo à corrupção, foram os principais proponentes do solidismo, como ficou conhecido esse modelo fisiológico. As suas teorias foram desenvolvidas pelos mecanicistas e vitalistas, cujos debates não conduziram a consenso. Na sequência dos trabalhos de Boerhaave, Albrecht von Haller (1708-1777) explicou os fenómenos fisiológicos como decorrentes de forças vitais básicas: a irritabilidade, localizada nos músculos, e a sensibilidade, situada nos nervos. A teoria da força vital foi desenvolvida por William Cullen (1710-1790), que concebeu os nervos e os músculos integrados num único sistema, o nervoso, no qual residia a causa das doenças. Por sua vez, os vitalistas, como François Boissier de Sauvages de Lacroix (1706-1767), argumentavam que cada órgão tinha uma única força vital que garantia o seu funcionamento. A teoria solidista considerava os vasos sanguíneos e os nervos como tubos pelos quais os fluidos percorriam o corpo, de maneira proporcional ao tónus das suas fibras. Assim, o corpo era saudável quando os fluidos podiam circular sem obstruções para não fermentar e provocar a doença (Porter, 1995, p.375-397; Estes, 2000, p.1538; Broman, 2003, p.469-480; Lindemann, 2010, p.106-109; Foucault, 1980; Ishizuka, 2012). Importa sublinhar que o solidismo, constituindo um quadro conceptual alternativo, não excluiu a fisiologia humoral e, frequentemente, conviveu com ela (Estes, 2000, p.1538). Os médicos continuaram a combinar conceitos oriundos de várias teorias fisiológicas para explicar a doença, cuja origem permanecia multifactorial.

Concomitantemente, os estudos químicos conduziram a um progressivo conhecimento da composição dos alimentos e à diferenciação de grupos alimentares, mesmo que eles tivessem sido melhor explicitados apenas no decurso do século XIX ou até depois. Por exemplo, Boerhaave distinguia os alimentos posteriormente designados por proteínas (1838) e carboidratos (1844), enquanto Haller identificou um outro grande conjunto de alimentos, as gorduras, mostrando que eram emulsionadas pela bílis (Estes, 2000, p.1539). Assim, não 
só havia novas perspectivas médicas sobre o corpo, mas também sobre os alimentos, os quais também eram debatidos sob diversas perspectivas, incluindo à luz da química. Isso modificava o entendimento que o humoralismo fizera deles e do seu papel na saúde dos indivíduos (Ferrières, 2002, p.365-370; Spary, 2012).

A passagem dos humores às fibras e aos nervos nas teorias médicas e um melhor conhecimento sobre os alimentos reordenaram as questões dietéticas. Não elidindo as qualidades que lhes eram atribuídas pelo humoralismo, cada vez mais, a avaliação dos alimentos tinha em conta se relaxavam ou enrijeciam as fibras e os nervos, ou se diluíam o estímulo ou eram demasiado estimulantes (Vigarello, 2012, p.161-190). Ainda assim, não existia consenso sobre a alimentação, antes vários modelos em competição, os quais conformavam a prática médica e circulavam em livros destinados ao público. Alguns médicos aprovavam dietas frugais e, sobretudo, a exclusão de condimentos. Para certos doentes, insistiam no consumo de carnes leves, como a de galinha, e de peixes brancos. Outros recomendavam o aumento das porções de alimentos estimulantes, nomeadamente a carne, para, por exemplo, tratar doentes febris e debilitados. Outros, ainda, consideravam que os médicos regulavam demasiado a comida dos doentes, que deviam ter liberdade de escolha. A partir do século XVIII, os hospitais europeus adoptaram dietas estandardizadas baseadas no humoralismo e no solidismo, que se traduziram em rações inteiras, médias e leves, consoante a idade e a doença dos indivíduos internados (Estes, 2000, p.1538-1539; Smith, 2002; Beatty, 2012, p.103-105).

\section{O Real Hospital da Ilha de Moçambique e os seus doentes}

No início de Oitocentos, o Real Hospital da Ilha de Moçambique, na África Oriental, fundado pela Coroa portuguesa em Quinhentos, era uma instituição civil e militar. A sua área de actuação era constituída pela Ilha de Moçambique e pelas povoações localizadas no litoral fronteiro, embora pudessem chegar aí enfermos de outros pontos da colónia, que compreendia, ainda, Cabo Delgado, Sofala, Inhambane e Lourenço Marques, no litoral, e a região continental ao longo do rio Zambeze. No seu conjunto, a população de Moçambique era bastante diversificada. Nela se incluía uma larga maioria de africanos de vários grupos étnico-linguísticos, os quais, na área da Ilha de Moçambique, eram macuas e suaílis, estes de influência cultural islâmica. Os colonizadores europeus, quase só homens, chegavam de Portugal e de territórios do império português. Das partes do Índico, sobressaíam os goeses e indo-portugueses, assim como uma comunidade de mercadores baneanes com origem, sobretudo, em Diu (Rodrigues, 2010).

Entre os admitidos no hospital, salientavam-se os soldados das companhias da ilha, enquanto as restantes categorias constituíam uma minoria. Com efeito, tal como na Europa, os moradores de Moçambique tratavam-se, habitualmente, em casa, podendo socorrerse de praticantes das medicinas que circulavam aí, desde a europeia, às indianas (de base ayurvédica e muçulmana) ou à africana, incluindo também a de origem muçulmana. Em geral, apenas os mais pobres, suportados pela Misericórdia, chegavam a ser internados. ${ }^{3}$ A imensa maioria de africanos consultava os seus próprios terapeutas. Regularmente, apenas os escravos pertencentes à Coroa portuguesa frequentavam o hospital. Para além dos residentes, também os passageiros das embarcações que aportavam à ilha eram assistidos na instituição. 
As estatísticas disponíveis são fragmentárias e, orientadas por objectivos orçamentais, revelam-se insuficientes para caracterizar os doentes e as doenças. Dados relativos a 1819 e 1821 indicam que, entre 1.455 doentes, 1.195 (82,1\%) eram militares; 161 (11,1\%), escravos; 71 (4,9\%), pobres da Misericórdia; e 28 (1,9\%), particulares (Simoni, 1858, p.92). Embora esses mapas não o informem, o conjunto de enfermos integrava indivíduos de diferentes origens étnicas, que constituíam a sociedade colonial. Entre os militares tanto se encontravam europeus e goeses como mestiços de famílias locais ou macuas e suaílis, os dois últimos compondo companhias que actuavam no litoral da Ilha de Moçambique. Os escravos eram, claro, africanos. Quanto aos doentes particulares e aos apoiados pela Misericórdia, tudo indica que eram vulgarmente europeus, indo-portugueses e mestiços.

Que tipo de doenças acometia os internados no hospital? Russel C. Maulitz (2002, p.19-20) destacou a complexidade de apreender as categorias de diagnóstico construídas pela medicina pré-bacteriológica anterior ao final do século XIX. Conquanto múltiplos nomes de doenças do passado existam ainda hoje, a sua classificação nosológica foi-se reconfigurando, e diversas entidades mórbidas anteriores desapareceram ou foram substituídas no vocabulário médico.

Conforme as perspectivas dos princípios de Oitocentos, grande parte das doenças era vista como estando relacionada com problemas gastrointestinais e respiratórios. Em 1817, um cirurgião atestava que "as febres, que costumam grassar com frequência neste país, quase todas têm a sua sede ou no estômago, ou nos intestinos" (Gonçalves, 14 set. 1817). Pouco depois, um físico-mor reportava como doenças mais frequentes as catarrais e as biliosas, as primeiras devido à humidade e as segundas ao calor (Simoni, 1821, fl.181v). Os factores ambientais, conforme as concepções neo-hipocráticas, assumiam uma grande importância na explicação da doença, sobretudo nos climas quentes. Por exemplo, a tónica colocada nas enfermidades biliosas e gástricas derivava da ideia de que o fígado era aí mais sensível, enquanto a produção de bílis era superior à necessária à digestão, o que originava doenças como febres e disenterias (Harrison, 2013, p.62-63; Arnold, 2004, p.76-79).

A primeira estatística nosológica hospitalar disponível, concernente ao ano de 1844-1845, relaciona 726 doentes. O Quadro 1 considera as doenças com mais de cinco ocorrências aí contidas, agregando em "outras" as que apresentaram um número de casos inferior.

As classificações que estruturaram esse mapa indicam que o grupo dominante de enfermidades era o das febres, distinguidas em vários tipos. Saliente-se que, conforme as nosologias coevas, muitas doenças eram qualificadas como febres, divididas em várias categorias (Bynum, 1981). Das febres moçambicanas, as mais numerosas eram as intermitentes, geralmente associadas à malária (Lindemann, 2010, p.115). Essa estatística também aponta a prevalência de múltiplas doenças relacionadas com desordens gástricas e respiratórias, incluindo algumas febres, coincidindo com as perspectivas dos observadores anteriores. Periodicamente, esta região também era acometida por epidemias de bexigas e sarampo (Simoni, 1821, fl.185; Mártires, 1823, fl.41), que atingiam, sobretudo, os africanos, em particular os destinados ao tráfico. Porém, esse tipo de doença era tratado, preferencialmente, fora do hospital. Por exemplo, os escravos que chegavam com varíola eram mantidos em quarentena nos navios e em lazaretos temporários (Mendonça, 4 jul. 1811). Vários testemunhos ressaltaram, ainda, doenças que consideravam específicas de África. Era o caso da cheringosa (Simoni, 1821, fl.237v), decorrente de formas graves de disenteria, que acometia especialmente os africanos. 
Quadro 1: Doenças tratadas no hospital (novembro de 1844-outubro de 1845)

\begin{tabular}{|l|r|l|r|l|r|}
\hline Doença & Total & Doença & Total & Doença & Total \\
\hline Bubão sifilítico & 5 & Febre gástrica & 30 & Pletora & 5 \\
\hline Catarro bronquial & 8 & Febre catarral & 5 & Pleurites & 8 \\
\hline Colite & 5 & Febre intermitente & 122 & Pleuroperipneumonia & 7 \\
\hline Contusão & 18 & Ferido de instrumento & 5 & Reumatismo crónico & 8 \\
\hline Diarreia & 15 & Gastrite & 69 & Splenite aguda & 19 \\
\hline Diátese sifilítica & 14 & Gastroenterite & 18 & Úlcera atónica & 21 \\
\hline Disenteria & 18 & Gastrosplenite & 15 & Úlcera gangrenosa & 5 \\
\hline Embaraço gástrico & 24 & Hemorroide & 6 & Úlcera sifilítica & 15 \\
\hline Exantema & 7 & Hepatite aguda & 17 & Úlcera escorbútica & 9 \\
\hline Febre atáxica & 9 & Laringite & 5 & Uretrite & 8 \\
\hline Febre adinâmica & 12 & Obstrução do splen (baço) & 14 & Velhice & 6 \\
\hline Febre angioténica & 8 & Obstrução do fígado & 9 & Outras & 102 \\
\hline Febre contínua & 20 & Oftalmia catarral & 8 & & \\
\hline Febre biliosa & 21 & Ptisis pulmonar & 6 & Total Geral & 726 \\
\hline
\end{tabular}

Fonte: Salis, 1 nov. 1845

Essa doença, chamada do bicho ou maculo no Atlântico, é identificada na actualidade como anite e rectite inflamatórias, por vezes, associada a miíases (Sousa, 2013, p.217-219). Entre essas moléstias estava, ainda, o mordexim (Simoni, 1821, fl.234v), o nome usado no Índico para a cólera-morbo.

No início de Oitocentos, o hospital sofrera um conjunto de reformas que, no âmbito da polícia médica conduzida pelos Estados absolutistas europeus (Rosen, 1980), tentavam transpor as normas europeias para o império. Em 1763, a gestão do hospital transitou dos religiosos de são João de Deus para a administração régia. A partir da década de 1780, ocorreram esforços para recrutar médicos e cirurgiões formados, embora a elevada mortalidade dos europeus deixasse lugar a que, por vezes, a assistência médica recaísse sobre profissionais munidos apenas com uma aprendizagem prática. Nessa mesma década, foram elaborados regimentos hospitalares, que visavam maior controlo dos doentes pelo pessoal médico e pela administração, de modo a assegurar uma melhor assistência, e outras reformas prosseguiram nas primeiras décadas de Oitocentos (Rodrigues, 2013; Rodrigues, Brito, 2013).

\section{Doentes e dietas}

Como as ideias médicas sobre a dieta circularam entre a Europa e os seus impérios e foram aí aplicadas, passando, eventualmente, por um processo de acomodação? Nomeadamente, de que forma a progressiva transformação das perspectivas médicas sobre a alimentação condicionou o modo de nutrir os doentes no contexto específico do hospital de Moçambique?

As reformas da década de 1780 incidiram também sobre as dietas dos enfermos, mas constituíram um compromisso entre as teorias médicas europeias e as práticas alimentares vigentes no hospital, que incluíam comidas bastante temperadas. As informações sobre a alimentação hospitalar, antes dessa reforma, sugerem uma vinculação às práticas culinárias locais, que integravam tradições portuguesas, indianas e, menos, africanas (Rodrigues, no 
prelo). No regulamento de 1788 , as refeições organizavam-se em rações inteiras, meias e de um quarto, correspondendo a diferentes quantidades e tipos de comida (Regimento..., 30 dez. 1788). Mas esse menu conservava modos de cozinhar enraizados na região. Assim, a refeição da manhã, o almoço, variava entre a canja, o caldo de pão e a açorda. A canja, de origem indiana, era composta por arroz muito cozido em água e sal, sendo dada aos doentes, "como alimento fraco e de fácil digestão" (Dalgado, 1919-1921, v.1, p.206-207). O caldo de pão, açucarado, e a açorda eram oriundos da tradição portuguesa.

As refeições do jantar, a principal do dia, consistiam em caldo de galinha com pão ralado, para o quarto de ração; atola, peixe e pão, no caso da meia ração; e arroz-caril, galinha e pão, para a ração inteira. O caldo de pão, a atola e a atola com peixe e pão eram prescritos para a ceia. Também nestas ementas convergiam diferentes tradições. $\mathrm{O}$ arroz era o cereal mais usado na ilha pelos reinóis e goeses, e as formas de o cozinhar derivavam, principalmente, da tradição indiana. A atola consistia numa "iguaria, feita de legumes e arroz" (Silva, 1948, v.2, p.199). ${ }^{4}$ O arroz-caril, confeccionado com especiarias e moedura de coco, era característico de Goa e estava muito difundido em Moçambique. O outro cereal que constituía a base da alimentação hospitalar era o trigo, servido em pão, como em Portugal. No entanto, devido à sua escassez, era frequentemente trocado por mucates, o pão de milho-miúdo preparado à africana. A galinha era a carne fornecida aos doentes, pois, em Moçambique, era difícil encontrar borrego e boi, preferidos nos hospitais de Portugal. Todavia, dada a sua penúria no mercado, ela era amiudadamente substituída por peixe. A inclusão de pescados na dieta dos doentes era, porém, mal vista, dados os prejuízos que o davam como alimento corruptor (Rodrigues, 2013). Esse padrão dietético introduzia uma certa homogeneização na comida hospitalar, conquanto continuasse a conceder lugar aos gostos culinários locais.

Tudo indica que esse modelo de alimentação foi mantido nos anos seguintes, embora as relações de compras do hospital sugiram a introdução progressiva de outros géneros. Assim, o almoço passou a incluir também papas de rolão, ou seja, a farinha de trigo com farelo, como se praticava em Moçambique; a olanga, isto é, o polvilho da mandioca; e o sagu, uma fécula extraída do caule de palmeira, muito usada no Oriente. Nessas listas, também consta a compra de pequenas quantidades de doces e frutas (Relação..., 24 nov. 1808).

A vinculação da culinária hospitalar à sociedade foi ainda mais erodida pelos físicos-mores que actuaram na segunda década de Oitocentos. Conforme sublinhou C. Bastos (2011, p.32), em relação aos médicos coloniais, também na actividade e na produção escrita dos clínicos que trabalharam em Moçambique é possível apreender "o estado da arte mobilizado para a prática, como que um retrato em movimento da ciência em acção".

Médicos como António José de Lima Leitão (1787-1856) e Luís Vicente de Simoni (17921881) ensaiaram aplicar em Moçambique os desdobramentos da medicina europeia, intervindo na dieta dos enfermos. Leitão era um cirurgião que fora mobilizado para o exército napoleónico quando este invadiu Portugal (1808), tendo-se formado em medicina na Universidade de Paris, então, o principal centro europeu de inovação médica. Regressado a Portugal, em 1814, transportou-se para o Rio de Janeiro, onde estava a corte. Apontado como físico-mor de Moçambique, em 1816, manteve-se nesse cargo até 1818 (Bastos, 2011, p.27-28). Sucedeu-lhe Simoni, natural da República de Génova, o qual se diplomara, em 1815, na universidade dessa cidade. Ele também viajou para o Brasil e, em 1819, foi nomeado físico-mor de Moçambique, 
onde permaneceu até 1821 (Rodrigues, 2006). Apesar de diferentes trajectórias, esses médicos formaram-se, no mesmo período, em instituições de ensino similares, beneficiando-se de uma formação académica semelhante. Com efeito, com a incorporação da Itália no império de Napoleão, a Universidade de Génova passou a integrar a Academia Imperial, que tinha como modelo a universidade parisiense (Farinella, 2003).

Esses médicos estavam convictos da hegemonia da medicina europeia, mesmo que tentassem dialogar com os conhecimentos locais, pelo que tentaram configurar a sua experiência africana pela ciência europeia. Conforme as ideias neo-hipocráticas, nos climas quentes, como era o de Moçambique, o tipo de dieta era especialmente visto como um factor de propensão ou agravamento da doença (Arnold, 2013, p.86). Empunhando a sua autoridade médica, ambos introduziram no hospital novas ementas, que apontavam para uma mudança nas práticas alimentares dos enfermos. Leitão estabeleceu um novo plano de dietas em 1817, o qual foi modificado, em 1820, por Simoni (Quadros 2 e 3).

Essas ementas partilhavam orientações, mas também apresentavam diferenças. A lista de Leitão dividia-se em dez rações, reservando as quatro últimas para o almoço, a refeição da manhã, enquanto as restantes se repetiam ao jantar e à ceia, com uma menor quantidade na refeição da noite. O menu elaborado por Simoni organizava as rações em 24, não as distinguindo por refeição e incluindo nesse número porções de alimentos como pão, açúcar, vinho etc., que já antes eram servidas como extraordinárias e, na verdade, continuaram a ser arroladas como tal. Com efeito, esses planos previam a disponibilização de alimentos extraordinários, conforme as determinações dos médicos. Ambos os planos conservaram os alimentos básicos servidos no hospital, o arroz e o pão trigo, acompanhados de galinha ou peixe. Note-se, ainda, que foi introduzido um prato de ervas, conforme a progressiva valorização das verduras, antes consideradas indigestas, na Europa (Flandrin, 2001b, p.238-240).

A análise das comidas efectivamente servidas fornece uma imagem mais aproximada das práticas alimentares no hospital. Para isso, considere-se março de 1817, quando foi introduzido o primeiro plano, e o mesmo mês em 1820. Quanto ao almoço, Leitão privilegiou o sagu, 70,7\%

Quadro 2: Dietas diárias no hospital, 1817

\begin{tabular}{|c|c|c|c|c|}
\hline \multicolumn{3}{|c|}{ Plano das dietas } & \multicolumn{2}{|c|}{$\begin{array}{l}\text { Dietas ordinárias, } \\
\text { março }\end{array}$} \\
\hline & No & Ração & Total & $\%$ \\
\hline \multirow[t]{6}{*}{ Jantar e Ceia } & 1 & J/C: caldo de galinha. & 88 & 8,2 \\
\hline & 2 & J: caldo, pão, arroz; C: caldo, arroz. & 210 & 19,6 \\
\hline & 3 & J/C: um quarto de galinha, arroz, pão. & 692 & 64,6 \\
\hline & 4 & J: meia galinha, arroz, pão; C: um quarto de galinha, arroz, pão. & 54 & 5,0 \\
\hline & 5 & J/C: prato de ervas, manteiga, vinagre, pão. & 26 & 2,4 \\
\hline & 6 & J/C: peixe, azeite, vinagre, pão. & 2 & 0,2 \\
\hline \multirow[t]{4}{*}{ Almoço } & 7 & Sagu, açúcar. & 268 & 70,7 \\
\hline & 8 & Rolão, açúcar. & 72 & 19,0 \\
\hline & 9 & Arroz, manteiga. & 25 & 6,6 \\
\hline & 10 & Chá com açúcar, pão torrado, manteiga. & 14 & 3,7 \\
\hline
\end{tabular}

Fonte: Leitão, 1 mar. 1817; Registo..., mar. 1817 
Quadro 3: Dietas diárias no hospital, 1820

\begin{tabular}{|c|c|c|c|c|c|}
\hline \multirow{2}{*}{\multicolumn{2}{|c|}{ Plano das dietas }} & \multicolumn{4}{|c|}{ Dietas ordinárias, março } \\
\hline & & \multicolumn{2}{|c|}{ Jantar e Ceia } & \multicolumn{2}{|c|}{ Almoço } \\
\hline $\mathrm{N}^{\circ}$ & Ração & Total & $\%$ & Total & $\%$ \\
\hline 1 & Caldo de galinha & 68 & 2,2 & & \\
\hline 2 & Água de arroz & 0 & 0,0 & & \\
\hline 3 & Caldo de galinha com arroz desfeito & 1024 & 32,8 & & \\
\hline 4 & Açorda de pão (pão, manteiga) & 5 & 0,2 & & \\
\hline 5 & Canja, galinha, pão & 1190 & 38,1 & & \\
\hline 6 & Canja de arroz, galinha (ou vaca, ou carneiro), pão & 569 & 18,2 & & \\
\hline 7 & $\begin{array}{l}\text { Arroz cozinhado enxuto com tempero, galinha (ou vaca, ou } \\
\text { carneiro), pão }\end{array}$ & 149 & 4,8 & & \\
\hline 8 & Arroz, guisado de moelas, pão biscoitado & 28 & 0,9 & & \\
\hline 9 & Arroz, peixe, se cozido, temperado com azeite e vinagre & 30 & 1,0 & & \\
\hline 10 & Arroz enxuto, ervas, pão, manteiga, vinagre & 40 & 1,3 & & \\
\hline 11 & Papa de sagu & 12 & 0,4 & 324 & 35,3 \\
\hline 12 & Papa de rolão & 4 & 0,1 & 594 & 64,7 \\
\hline 13 & Chá, açúcar, pão & 2 & 0,1 & & \\
\hline 14 & Café, açúcar & & & & \\
\hline 15 & Pão & & & & \\
\hline 16 & Leite & & & & \\
\hline 17 & Açúcar & & & & \\
\hline 18 & Manteiga do reino & & & & \\
\hline 19 & Canela, pimenta redonda & & & & \\
\hline 20 & Vinho & & & & \\
\hline 21 & Cerveja & & & & \\
\hline 22 & Frutas & & & & \\
\hline 23 & Chocolate & & & & \\
\hline 24 & Marmelada & & & & \\
\hline
\end{tabular}

Fonte: Simoni, 1 jan. 1820; Registo..., mar. 1820

das doses servidas, seguindo-se o rolão, o arroz e manteiga e o chá com torradas, este último reservado aos oficiais. Simoni preferiu alimentar os doentes, predominantemente, com chá e pão: 64,7\%. Quanto às refeições principais, em 1817, a galinha, o arroz e o pão, preparados de diversos modos, constituíram 97,6\% das doses ordinárias, mantendo-se essa opção em 1820, com $97,2 \%$. As verduras e o peixe tiveram uma expressão insignificante nos dois anos: as primeiras variando de $2,4 \%$ para $1,3 \%$, e o segundo passando de $0,2 \%$ para $1 \%$. Todavia, em 1820, foram abonadas mais 253 doses de peixe e 163 de ervas como extraordinárias, totais muito superiores aos da prescrição ordinária. Note-se, que, além de ter aumentado as porções de arroz e pão, de quatro (cerca de 114,7g) para seis onças (cerca de 172,1g), Simoni acrescentava, frequentemente, à dieta quantidades extraordinárias de alimentos, como galinha, sagu, doce, frutas ou açúcar. 
A principal mudança em ambos os planos residiu na opção por uma culinária simples, em que o processo de confecção hegemónico era a cozedura, com nenhum ou poucos temperos. Apenas o menu de Simoni admitia um arroz temperado e um guisado de moelas, ambos com uma expressão reduzida, num total de 5,7\%. Leitão substituiu, em poucos casos, a galinha cozida pela assada e guisada. Iguarias mais condimentadas até então presentes na dieta, como atola e, sobretudo, caril, foram banidas nesses menus. Introduzia-se uma diferença notória entre a alimentação dos doentes e aquela que era habitual na Ilha de Moçambique. Assim, a perspectiva desses médicos sobre a dieta traduzia-se na separação da comida dos doentes das práticas alimentares da sociedade moçambicana, contribuindo para a distinção entre doença e saúde.

No seu conjunto, essas ementas aproximavam a dieta dos enfermos de Moçambique daquela dos hospitais da Europa quanto ao modo de confecção dos alimentos, embora a escolha dos géneros permanecesse fortemente condicionada pelo mercado. ${ }^{5}$ Com efeito, nos hospitais de Inglaterra, no final de Setecentos, o alimento básico era o pão, fornecido nos caldos, em pudim ou inteiro, enquanto as carnes providas eram o boi e o carneiro (Estes, 2000, p.1538-1539). Por volta de 1800, no noroeste de Espanha, as dietas hospitalares incluíam carne de boi ou carneiro, pão, grão-de-bico e toucinho, consumo que era semelhante ao de outros hospitais espanhóis (Pérez Álvarez, 2010). Em Portugal, o regimento dos hospitais militares, de 1805, estabelecia rações de arroz, pão, carne de boi, vitela e carneiro. O peixe e os legumes, qualificados no texto regimental como indigestos, eram admitidos só aos convalescentes, se os médicos aquiescessem (Regulamento..., 2009).

\section{Discurso médico sobre a alimentação dos doentes em Moçambique}

Que teorias médicas subjaziam às opções dietéticas desses médicos? Ou seja, quanto à comida, como é que o discurso dos cientistas europeus foi apropriado pelos médicos "anónimos" (Bastos, 2011) e transposto para Moçambique? O conhecimento que temos acerca das perspectivas desses médicos é desigual. O facto de Leitão ter alterado a lista de menus indicia que ele concedia relevância à nutrição na cura dos enfermos e sugere que ele era adepto de uma dieta simples, mas, aparentemente, ele não registou as suas teorias sobre o tema. Nos seus textos sobre a cólera-morbo, da década de 1830, quando a epidemia atingiu Portugal, ele voltou à sua experiência em Moçambique e na Índia Portuguesa, onde trabalhou mais tarde. Nesses escritos, ele incluiu a dieta nas causas da doença, reportando a ingestão de "comidas corruptas, ou por outro qualquer modo nimiamente estimulantes" (Leitão, 21 set. 1831, p.914), o que indicia uma visão da alimentação enformada pelas perspectivas solidistas.

Já Simoni apresentou a sua abordagem das conexões entre alimentação e saúde na obra "Tratado médico sobre o clima e enfermidades de Moçambique" (Simoni, 1821). Esse tratado exemplifica o eclectismo das abordagens médicas, mobilizando concepções humorais, assim como teorias solidistas. Com efeito, ele tanto avaliou os alimentos em função dos temperamentos e das constituições quanto da acção estimulante ou debilitante, irritante ou relaxante que eles exerceriam sobre os sólidos e os fluidos do corpo.

Os seus escritos são vacilantes e, até, contraditórios. Atribuindo à doença causas múltiplas, ele concedia um lugar fundamental à alimentação, no seguimento daqueles ensinamentos 
e em articulação com as perspectivas europeias sobre a dieta nos países quentes. A discussão presente nesse tratado revela como os médicos não tinham atingido consenso sobre a alimentação e os seus efeitos sobre o corpo. Os seus debates organizavam-se em torno de várias autoridades e estendiam-se às perspectivas dos moradores da ilha sobre nutrimentos com os quais ele estava pouco familiarizado. Porém, frequentemente, Simoni acabava por refutar tanto a autoridade dos cientistas quanto as opiniões dos moradores, privilegiando a sua experiência em Moçambique.

Simoni sublinhava a importância da alimentação na saúde, argumentando que as "moléculas animalizadas, depois de ter por um certo tempo formado parte dela [a máquina do homem], separam-se novamente, deixando um vão para ser ocupado de outras. Eis aqui a necessidade indispensável de um alimento que forneça materiais idóneos a suprir a ocorrência das faltas" (Simoni, 1821, fl.110v). Tal como nos demais países quentes, em Moçambique, as perdas de moléculas eram elevadas, devido à acção da transpiração, o que reforçava o papel preventivo e terapêutico dos nutrimentos (fl.112).

Os alimentos tinham, então, a função de substituir essas moléculas perdidas, mas podiam revestir-se de um carácter benéfico ou destrutivo. Constituindo "agentes externos" ao corpo, na sequência dos não naturais do humoralismo, eles tinham, também, de ser considerados pela interacção com a "força vital dos seus órgãos" (fl.110v), que se opunha à sua destruição, conforme a abordagem dos vitalistas. Isso implicava considerar os alimentos na sua relação com o "temperamento, constituição, saúde ou enfermidade do indivíduo, ... hábitos, ocupações e apetites" (fl.111). Nesse quadro, os alimentos eram avaliados quanto à sua quantidade, qualidade, digestibilidade e efeitos (estimulantes, atonizantes, irritantes etc.) sobre os sólidos e fluidos corporais. Simoni explanou aqueles critérios relativamente a cada um dos géneros que compunham as práticas alimentares em Moçambique. Aqui interessa discutir os aspectos inscritos na nutrição dos enfermos internados no hospital.

Antes de mais, Simoni defendia que uma alimentação em quantidade suficiente era essencial para assegurar a saúde: "o corpo bem nutrido se achará continuadamente num estado favorável para resistir à violência das causas que tendem a extingui-lo, principalmente aquelas cuja acção directa é diminuir e consumir a sua vitalidade" (fl.111). Estando as enfermidades de Moçambique associadas, comumente, à debilidade e à diminuição da força vital (fl.111v), uma dieta em quantidade satisfatória contribuía não só para evitar a doença como para recuperar a saúde. Assim se compreende que Simoni tenha acrescentado as porções de alimentos anteriormente estipuladas por Leitão e lhes adicionasse, ainda, doses extraordinárias. Ele sugeria mesmo que o menor número de óbitos ocorridos durante o seu exercício se devia tanto à terapêutica por ele seguida, quanto à "maior fartura nas dietas" (fl.111v). Note-se, porém, que, aderindo a essa abundância, Simoni advogava moderação no consumo alimentar (fl.111), uma forma de controlar os não naturais. Com efeito, esse princípio, formulado na Antiguidade, manteve-se como uma ideia com grande estabilidade (Shapin, 2003).

A qualidade dos mantimentos era apreciada em função dos "materiais nutritícios" (Simoni, 1821, fl.112v) aí presentes. Assim, inserindo-se nos debates coevos, Simoni considerava haver alimentos que forneciam materiais aptos à formação da "substância animal", enquanto outros não, mesmo que contivessem muita "matéria nutritiva" (fl.112). Nessa altura, uma questão que ocupava a ciência era o processo de formação da "substância animal" - constituinte dos 
músculos, pele e fluidos - um conceito que antecipava o de proteína, cunhado em 1838, por Jöns Jakob Berzelius (Carpenter, 2000, p.882-883). A identificação de alimentos com "matéria nutritiva" aponta para os carboidratos, cuja denominação seria fixada posteriormente. Simoni (1821, fl.110v) distinguia, portanto, grupos de alimentos e, na sua apreciação da respectiva importância na dieta dos doentes, como se verá adiante, integrava aspectos da química para apontar aqueles mais prontamente "animalizados", isto é, assimilados pelo corpo.

Já a digestibilidade dos nutrimentos, medida pela sua dureza, servia para os classificar como leves ou moles, pesados ou duros, como indicara Avicena. Os alimentos pesados, independentemente da sua qualidade, deveriam ser evitados em Moçambique, onde a digestão era muito vagarosa, favorecendo a indigestão, a doença mais violenta que aí podia sobrevir (fl.112). Isso acontecia, dizia Simoni, devido ao estímulo que o calor provocava na epiderme, concentrando nela a "força vital" e reduzindo-a nos órgãos internos. Simoni apontava, principalmente, para o modo como a atmosfera quente e húmida de Moçambique agia sobre os tecidos, provocando, entre outros aspectos, uma transpiração excessiva, que aglutinava na pele a "força vital", conduzindo os órgãos internos, como o estômago, à decomposição (fl.182v). Essa era uma discussão que prendia os médicos, que olhavam o metabolismo do corpo humano em função de estímulo-resposta, além de que os estudos da fisiologia da digestão, a partir dos trabalhos de Antoine Lavoisier (1743-1794), tinham mostrado um aumento do consumo de oxigénio durante esse processo (Porter, 1995, p.389), também isso exigindo força vital. Assim, Simoni (1821, fl.112v) advogava o uso de alimentos ligeiros em Moçambique, princípio que reforçou largamente em relação aos enfermos.

Considerando as qualidades nutritivas, grau de digestibilidade e efeitos sobre sólidos e fluidos, que alimentos privilegiava Simoni para integrar a dieta hospitalar?

A alimentação dos doentes devia ser leve, atendendo ao seu estado debilitado, em que a "força vital" dos órgãos estava menos activa, e, simultaneamente, fornecer as matérias nutritivas necessárias. Claramente, Simoni (1821, fl.112v) privilegiava o consumo do trigo e dos alimentos preparados com ele, como o pão e as massas, ambos bens de luxo em Moçambique. Nesse ponto, ele abraçava os progressos ocorridos no conhecimento da composição química do cereal. Em 1728, o químico italiano Jacopo Bartolomeo Beccari (1682-1766) identificara o glúten como uma substância semelhante àquela de origem animal, diversa das matérias amiláceas típicas dos vegetais. O trigo passou a ser conhecido como "carne vegetal" (Carpenter, 2000, p.883), por entrarem na sua composição os princípios azotados. Simoni (1821, fl.116), seguindo os ventos da química, classificava-o como "alimento vegetal e animal", enaltecendo a combinação da fécula vegetal com o princípio glutinoso, a substância mais próxima da gelatina, "material o mais nutriente que contêm as substâncias animais". Esse alimento completo era, portanto, o mais adequado ao homem. E era especialmente recomendável em Moçambique, uma vez que podia substituir a própria "substância animal" fornecida pelas carnes, difíceis de obter e de conservar na região. ${ }^{6}$ Justificava-se, assim, o emprego do pão de trigo no hospital e a rejeição dos mucates de milho-miúdo, muito indigestos devido à matéria sílica encontrada na casca: "Os mucates são o alimento que causa os maiores danos em Moçambique. As recaídas da maior parte dos enfermos que saem do hospital são devidas a esta massa indigesta e ordinariamente mal feita e mal cozida, que sucede ao uso de um alimento são e ligeiro durante a moléstia" (fl.115). 
Essa valorização do trigo parece explicar por que ele privilegiou o rolão no almoço dos doentes e aumentou a quantidade do pão suprido nas restantes refeições. A par do trigo, Simoni analisava outros amiláceos usados no hospital, aprovando as féculas servidas ao almoço (olanga e sagu) por serem ligeiras, tal como o arroz, presente na generalidade dos menus. Ele, em particular, favorecia a inclusão do arroz na dieta, por o considerar leve e, portanto, insusceptível de causar danos: "Porém, se o arroz fornece pouco nutrimento, este ao menos é ligeiro e bom e susceptível, por isso, de causar menos prejuízos. A sua combinação com as substâncias mais nutrientes é mais abraçada pelo estômago do que outra qualquer. Isto justifica a vantagem do seu grande uso em Moçambique e o emprego dele no hospital como base da dieta" (fl.114v).

Não obstante, contendo limitada "matéria nutritícia", o arroz tinha de ser combinado com outros alimentos, aptos a fornecer a "substância animal" (fl.112). Aparentemente, Simoni privilegiava as carnes de boi e carneiro, em uso nos hospitais europeus, o que o levou a incluílas no plano das dietas. Mas, dada a sua escassez em Moçambique, ele abonava o emprego de galinha, de tradição local, ainda que a achasse pouco nutriente (fl.116v). Ele recomendava, então, a combinação do arroz com o peixe, que podia fornecer o azoto (antiga denominação do nitrogénio), a base da "substância animal", o qual as experiências de Alexander von Humboldt (1769-1859) e Jean-Michel Provençal (1781-1845) tinham mostrado, em 1808, existir no peixe. ${ }^{7}$ Assim, a inclusão do peixe na dieta dos enfermos, mal vista pela medicina humoral, apresentava-se, agora, como justificada pela ciência. Essa perspectiva explica por que o médico prescrevia inúmeras doses de peixe, servidas como extraordinárias.

Finalmente, Simoni (1821, fl.123v) era um férreo partidário da ingestão de hortaliças. Considerando "o ricto herbívoro assaz conveniente em Moçambique", ele combatia os preconceitos locais, que representavam a ingestão dos verdes como pouco nutriente e causa de desordens gástricas. Simoni qualificava-os como um alimento facilmente "animalizado" por, tal como o peixe, conterem azoto (fl.121). E, nessa medida, constituíam um nutrimento adequado às enfermidades resultantes da "alteração das substâncias animais no estômago e tubo intestinal e de uma grande alteração dos sólidos e dos humores do corpo, como parecem ser as febres adinâmicas e o escorbuto" (fl.123v). Simoni tinha em consideração, na avaliação dos verdes, como de outros alimentos, as doenças derivadas da deficiência alimentar, conquanto fosse necessário aguardar pelo século XX para explicitar a relevância de vitaminas e minerais na saúde (Kiple, Ornelas, 2000, v.1, p.740). A ingestão de hortaliças, na opinião do médico, era imposta pelo próprio apetite, indicador da sua adequação terapêutica: "é impossível que muitas enfermidades com que ela o pede sejam curadas com outro alimento exclusivo" (Simoni, 1821, fl.123). Todavia, ele argumentava que a necessidade de comer hortaliças dependia da dieta habitual dos indivíduos: os que se sustentavam de arroz e peixe careciam menos delas do que aqueles que utilizavam carnes muito nutrientes, como a de porco. O consumo tinha de adequar-se, igualmente, ao temperamento: precisava ser superior nos indivíduos sanguíneos e biliosos e reduzido nos fleumáticos, que deviam juntar-lhe algum estimulante, como especiarias (fl.123v). A valorização das verduras por Simoni reflectia uma alteração das perspectivas europeias sobre os vegetais, que, como foi referido para o caso português, não estava generalizada a todos os meios médicos. Mas Simoni era oriundo da Itália, onde os vegetais estiveram sempre mais divulgados do que no resto da Europa (Gianetti, 2010). 
Essa representação dos verdes explica o seu elevado consumo, em doses extraordinárias, durante o exercício de Simoni no hospital.

O banimento da dieta hospitalar de pratos muito condimentados, como o caril, por ambos os médicos, vinculava-se às perspectivas solidistas sobre a alimentação. Conforme Simoni (1821, fl.116v), esse tipo de comida irritava "a vitalidade dos órgãos". A representação das especiarias como pouco saudáveis, depois de encaradas como medicinais e correctoras dos alimentos, fazia caminho na Europa. Elas eram agora avaliadas, também, pela sua imputada acção irritante sobre os órgãos, embora Simoni ainda as pudesse considerar úteis como estimulantes. Com efeito, médicos destacados tinham condenado a utilização de certos condimentos por depauperarem os tecidos, enfraquecendo o corpo (Porter, 1995, p.418; Flandrin, 2001c, p.267-271; Beatty, 2012, p.103-104). A transposição dessa narrativa para Moçambique, operada pelos dois médicos, resultava na eliminação da dieta dos doentes de pratos inscritos nas tradições culinárias da região e contribuía para definir socialmente o doente e a doença.

Simoni não chegou a formalizar uma diferenciação das dietas consoante as doenças, mesmo considerando que, nessa individuação, teriam de ser tidos em conta outros elementos como o temperamento, a constituição ou os hábitos individuais. Ainda assim, o seu tratado fornece indícios sobre essa questão. Por exemplo, ele aprovava o uso que os moradores de Moçambique faziam de papas de sagu no tratamento de doenças pulmonares e intestinais. Ele também concordava com a opção de alimentar os doentes de disenteria com papas de olanga, tal como com o uso dessa fécula para engrossar o caldo servido aos febris (Simoni, 1821, fl.115-115v). Considerando o seu parecer sobre a valia das hortaliças no tratamento de febres adinâmicas e do escorbuto, é provável que ele as incluísse na dieta desses enfermos.

\section{Considerações finais}

Durante longo tempo, a dieta dos doentes internados no Real Hospital da Ilha de Moçambique esteve vinculada às práticas alimentares construídas na região. Tudo indica que essa alimentação era enformada pelas perspectivas médicas humoralistas, que, com formulações diferentes, orientavam igualmente a medicina europeia, a ayurvédica, ou a muçulmana, que circulavam em Moçambique. As práticas alimentares do hospital foram reconfiguradas a partir das últimas décadas de Setecentos e, mais acentuadamente, no princípio de Oitocentos. Através da prescrição das refeições, os médicos europeus visavam alimentar os doentes de acordo com os novos desenvolvimentos das teorias médicas europeias, nomeadamente no campo da fisiologia e da química dos alimentos, e da sua adequação aos climas quentes. As dietas foram encaradas de acordo com as teorias solidistas, segundo os seus efeitos, não apenas sobre os líquidos, como no humoralismo, mas também sobre as fibras e os nervos do corpo. Ainda assim, preceitos dietéticos antigos persistiam, nomeadamente quando os médicos olhavam os alimentos em função do equilíbrio humoral e do temperamento dos indivíduos. Médicos anónimos a actuar em Moçambique reinterpretaram esses ensinamentos para os aplicar à dieta dos doentes, articulando-os com factores ambientais, como o calor e a humidade, e a sua acção sobre o corpo. A adopção dessas perspectivas, num contexto de 
reforço do poder médico sobre os doentes e a sua alimentação, traduziu-se na homogeneização das ementas e na exclusão de certas iguarias de tradição local da dieta hospitalar.

A imposição de modos de alimentar os enfermos baseados no discurso médico europeu assentou na autoridade construída por esses médicos, enquanto directores do hospital e curadores de doentes. No entanto, narrativas posteriores indiciam que, na ausência da autoridade dos físicos-mores europeus, havia um relaxamento na aplicação desses preceitos dietéticos, o que justificava a adopção de novas medidas sobre a alimentação dos enfermos.

\section{AGRADECIMENTO}

Este trabalho é financiado por Fundos Nacionais portugueses, através da Fundação para a Ciência e a Tecnologia (FCT), no âmbito do projecto HC/0121/2009, Tratado médico sobre o clima e enfermidades de Moçambique.

\section{NOTAS}

${ }^{1}$ Os textos de Galeno sobre a alimentação foram publicados em Grant (2000).

${ }^{2}$ A medicina humoral do período moderno considerava o corpo em termos dos naturais (partes que o constituíam, humores, temperamentos etc.), dos contranaturais (elementos que agiam contra as funções do corpo, como doenças e defeitos herdados) e dos seis não naturais, em que se incluíam, além da alimentação, o ar, o exercício e o repouso, o sono e o passeio, as retenções e as evacuações e as paixões do espírito.

${ }^{3}$ A Misericórdia tinha um hospital que foi desactivado em 1789, quando foi estabelecido um acordo com a Fazenda Real para que os doentes apoiados pela irmandade passassem a ser tratados no Hospital Real (Rodrigues, 2013).

${ }^{4}$ Dalgado dá também como atola um prato semelhante à jagrada, um doce feito com açúcar de coqueiro e algum legume (Dalgado, 1919-1921, v.1, p.124).

${ }^{5}$ Como os mercados fornecedores dos alimentos estavam sujeitos a flutuações, obstaram, não raro, à aplicação das prescrições médicas, assumindo uma importância não despicienda na configuração das dietas. Nos registos diários do hospital, refere-se a alteração dos alimentos prescritos, por não existirem no mercado, permanecendo o caso mais comum a substituição da galinha por peixe.

${ }^{6}$ Porém, o método de panificação usado em Moçambique, empregando o sumo de coqueiro, suscitava reservas de Simoni. Esse sumo, segundo ele, tornava o pão menos digerível, diminuindo a energia vital do estômago e dispondo às doenças gastrointestinais (Simoni, 1821, fl.118-118v).

${ }^{7}$ Simoni aludia, erradamente, a Percival. Os resultados dessas experiências foram divulgados em: Humboldt, Provençal (1808). O nitrogénio fora descoberto em 1772, por Daniel Rutherford (1749-1819) (Porter, 1995, p.388). Em 1816, François Magendie já estabelecera que o nitrogénio provinha da comida e não do ar, concluindo que as fontes dietéticas do nitrogénio eram essenciais para a saúde. Apenas em 1866, Carl von Voit mostrou que o nitrogénio se encontrava nos alimentos quer de origem animal, quer vegetal (Estes, 2000, p.1542; Carpenter, 2000, p.882-883).

\section{REFERÊNCIAS}

ARNOLD, David.

Dietetics, mimesis, and alterity: food in Asian medical traditions and East-West exchanges. In: Kumar, Deepak; Basu, Raj Sekhar (Ed.). Medical encounters in British India. New Delhi: Oxford University Press. p.80-97. 2013.

ARNOLD, David.

Science, technology and medicine in Colonial India. Cambridge: Cambridge University Press. 2004.

BASTOS, Cristiana.

Corpos, climas, ares e lugares: autores e anónimos nas ciências da colonização. In: Bastos, Cristiana; Barreto, Renilda (Org.). A circulação do conhecimento: medicina, redes e impérios. Lisboa: Imprensa de Ciências Sociais. p.25-58. Disponível em: https://www.imprensa.ics.ul.pt/download/ books/bastos_barreto/bastos_e_barreto/ circulacao.pdf. Acesso em: 5 mai. 2012. 2011.

BEATTY, Heather R.

Nervous disease in late eighteenth-century Britain: the reality of a fashionable disorder. London: Pickering \& Chatto. 2012. 
BROMAN, Thomas H.

The medical sciences. In: Porter, Roy (Ed.). The Cambridge history of science. v.4. Cambridge: Cambridge University Press. p.463-484. 2003.

BYNUM, William F.

Cullen and the study of fevers in Britain, 1760-1820. Medical History, Supplement n.1, p.135-147. 1981.

CARPENTER, Kenneth J.

Proteins. In: Kiple, Kenneth F.; Ornelas, Kriemhild Conèe (Ed.). The Cambridge world history of food. v.1. Cambridge: University of Cambridge Press. p.882-888. 2000.

CASTRO, Inês de Ornellas e.

Prática médica e alimentação nos textos portugueses seiscentistas. In: Costa, Palmira Fontes da; Cardoso, Adelino (Ed.). Percursos na história do livro médico. Lisboa: Colibri. p.73-91. 2011.

COOK, Harold.

Medicine. In: Park, Katharine; Daston, Lorraine (Ed). Early modern science. The Cambridge history of science. v.3. Cambridge: Cambridge University Press. p.407-434. 2008.

DALGADO, Sebastião Rudolfo.

Glossário luso-asiático. Coimbra: Imprensa da Universidade. 1919-1921.

ESTES, J. Worth.

Food as medicine. In: Kiple, Kenneth F.; Ornelas, Kriemhild Conèe (Ed.). The Cambridge world history of food. v.2. Cambridge: University of Cambridge Press. p.1534-1553. 2000.

FARINELLA, Calogero.

Accademie e università a Genova. In: Puncuh, Dino (Ed.). Storia di Genova: Mediterraneo, Europa, Atlantico. v.1. Génova: Società Ligure di Storia Patria. p.19-36. 2003.

FERRIÈRES, Madeleine.

Histoire des peurs alimentaires: du Moyen Âge à l'aube du XX siècle. Paris: Éditions du Seuil. 2002.

FLANDRIN, Jean-Louis.

Os tempos modernos. In: Flandrin, Jean-Louis; Montanari, Massimo. História da alimentação. v.2. Lisboa: Terramar. p.143-168. 2001a.

FLANDRIN, Jean-Louis.

Opções alimentares e arte culinária (séculos XVI-XVIII). In: Flandrin, Jean-Louis; Montanari, Massimo. História da alimentação. v.2. Lisboa: Terramar. p.237-260. 2001b.

FLANDRIN, Jean-Louis.

Da dietética à gastronomia, ou a libertação da gula. In: Flandrin, Jean-Louis; Montanari, Massimo. História da alimentação. Lisboa: Terramar. v.2. p.261-278. 2001c.
FLANDRIN, Jean-Louis; MONTANARI, Massimo. História da alimentação. Lisboa: Terramar. 2001.

FOUCAULT, Michel.

Naissance de la clinique. Paris: PUF. 1980.

GIANETTI, Laura.

Italian Renaissance food-fashioning or triumph of greens. Californian Italian Studies, v.1, n.2.

Disponível em: http://escholarship.org/uc/ item/1n97s00d. Acesso em: 5 fev. 2012. 2010.

GONÇALVES, Gaspar Francisco.

Atestação. Moçambique. Conselho Ultramarino, Moçambique; caixa 155, documento 83.

(Arquivo Histórico Ultramarino, Lisboa). 14 set. 1817.

GRANT, Mark.

Galen on food and diet. New York: Routledge. 2000.

HARRISON, Mark.

From bazaar medicine to hospital medicine:

Calomel, India, and the British Empire, c.1750-

1800. In: Kumar, Deepak; Basu, Raj Sekhar (Ed.). Medical encounters in British India. New Delhi: Oxford University Press. p.61-79. 2013.

HUMBOLDT, Alexander von; PROVENÇAL, JeanMichel.

Recherches sur la respiration des poissons. Memoires de Physique et de Chimie de la Société d'Arcueil, n.2, p.339-404. 1808.

ISHIZUKA, Hisao.

'Fiber body': the concept of fiber in eighteenthcentury medicine, c.1700-40. Medical History, v.56, n.4, p.562-584. Disponível em: http://www. ncbi.nlm.nih.gov/pmc/articles/PMC3483762. Acesso em: 1 nov. 2012. 2012.

KIPLE, Kenneth F.; ORNELAS, Kriemhild Conèe (Ed.).

The Cambridge world history of food. Cambridge: University of Cambridge Press. 2000.

LEITÃO, António José de Lima.

Esboço da doença, que, vinda da Ásia sob o nome de Cólera Morbus, reina epidémica hoje, e tão mortalmente na maior parte Setentrional da Europa. Gazeta de Lisboa, n.223, p.913-915. 21 set. 1831.

LEITÃO, António Lima.

Plano das rações que se porá em uso no Hospital Militar de Moçambique. Ilha de Moçambique. Fundo do Século XIX; códice 11.4780 Gd6, fl.48-49. (Arquivo Histórico de Moçambique, Maputo). 1 mar. 1817.

LINDEMANN, Mary. Medicine and society in early modern Europe. Cambridge: Cambridge University Press. 2010. 
MÁRTIRES, Bartolomeu dos, frei.

Memória corográfica da província ou capitania de Moçambique na costa d'África Oriental conforme o estado em que se encontrava no ano de 1822. Secção Especial; SEaIIIP9, n.216a. (Arquivo Histórico de Moçambique, Maputo). 1823.

MAULITZ, Russel C.

Morbid appearances: the anatomy of pathology in the early nineteenth century. Cambridge: Cambridge University Press. 2002.

MENDONÇA, António Manuel de Melo e Castro. Bando. Ilha de Moçambique. Conselho Ultramarino, códices; códice 1382, fl. 67-67v. (Arquivo Histórico Ultramarino, Lisboa). 4 jul. 1811.

PÉREZ ÁLVAREZ, Maria José.

Disease and health care in the North-West of Spain in the early Modern Period: the Bierzo region. Hygiea Internationalis, v.9, n.1, p.53-77. Disponível em: http://www.ep.liu.se/ej/hygiea/. Acesso em: 1 out. 2011. 2010.

PORTER, Roy.

The eighteenth century. In: Conrad, Laurence I. et al. The Western medical tradition: 800BC1800AD. Cambridge: Cambridge University Press. p.371-475. 1995.

REGIMENTO...

Regimento do Real Hospital da Ilha de Moçambique. Ilha de Moçambique. Conselho Ultramarino, Moçambique; caixa 56, documento 72. (Arquivo Histórico Ultramarino, Lisboa). 30 dez. 1788.

REGISTO...

Registo diário das dietas do Real Hospital. Ilha de Moçambique. Fundo do Século XIX; códice 11.4780 Gd6, fl.50-54. (Arquivo Histórico de Moçambique, Maputo). mar. 1817.

REGISTO...

Registo diário das dietas do Real Hospital. Ilha de Moçambique. Fundo do Século XIX; códice 11.4780 Gd6, fl.216-220. (Arquivo Histórico de Moçambique, Maputo). mar. 1820.

REGULAMENTO...

Regulamento para os hospitais militares, 1805.03.27. In: Borges, Augusto Moutinho.

Reais hospitais militares em Portugal (1640-1834). Coimbra: Imprensa da Universidade de Coimbra. p.178-200. 1.ed. 1805. 2009.

RELAÇÃO...

Relação de despesa do Real Hospital de 1799 até 1808. Ilha de Moçambique. Conselho Ultramarino, Moçambique; caixa 84, documento 83. (Arquivo Histórico Ultramarino, Lisboa). 24 nov. 1808.
RODRIGUES, Eugénia.

Eating and drinking at the Royal Hospital of Mozambique Island: medicine and diet change between the end of the eighteenth century and the early nineteenth century. Afriques, v.5. no prelo.

RODRIGUES, Eugénia.

O Real Hospital de Moçambique e as suas conexões goesas: homens, saberes e produtos. In: Matos, Artur Teodoro de; Cunha, João Manuel Teles da (Ed.). Goa: passado e presente. Lisboa: CEPCEP-CHAM. p.519-541. 2013.

RODRIGUES, Eugénia.

Colonial society, women and African culture in Mozambique, c.1750-1850. In: Sarmento, Clara (Ed.). From here to diversity: globalization and intercultural dialogues. Newcastle-Upon-Tyne: Cambridge Scholars Publishing. p.253-274. 2010.

RODRIGUES, Eugénia.

Alimentação, saúde e império: o físico-mor Luís Vicente de Simoni e a nutrição dos moçambicanos. Arquipélago-história, v.9-10, p.621-660. 2006.

RODRIGUES, Eugénia; BRITO, Miguel. Colonização e polícia médica em Moçambique no final do período moderno. In: Roque, Ana Cristina; Rodrigues, Eugénia (Org.). Congresso Internacional Saber Tropical em Moçambique, 2012, Lisboa. Actas... Lisboa: Instituto de Investigação Científica Tropical. 2013.

ROSEN, George.

Da polícia médica à medicina social: ensaios sobre a história da assistência médica. Rio de Janeiro: Graal. 1980.

SALIS, Jacques de.

Estatística das moléstias que foram tratadas no Hospital Militar de Moçambique durante o ano, desde $1^{\circ}$ de Novembro de 1844 até 31 de Outubro de 1845. Ilha de Moçambique. Secretaria de Estado da Marinha e Ultramar, Direcção Geral do Ultramar; caixa 1507. (Arquivo Histórico Ultramarino, Lisboa). 1 nov. 1845.

SHAPIN, Steven.

Trusting George Cheyene: scientific expertise, common sense, and moral authority in early eighteenth-century dietetic medicine. Bulletin of the History of Medicine, v.77, n.2, p.263-297. 2003.

SILVA, António de Morais.

Grande dicionário da língua portuguesa. Lisboa: Confluência. 1948.

SIMONI, Luís Vicente de.

Mortalidade nos enfermos tratados no Hospital Militar e Civil de Moçambique durante o tempo em que na qualidade de físico-mor dessa capitania dele foi médico o Dr. L.V. De Simoni. 
Anais Brasilienses de Medicina: Jornal da Academia Imperial de Medicina do Rio de Janeiro, v.12, n.3, p.90-92. 1858 .

SIMONI, Luís Vicente de.

Tratado médico sobre o clima e enfermidades de Moçambique. Secção de Manuscritos. Fundo De Simoni, códice I-47, 23, 17. (Biblioteca Nacional, Rio de Janeiro). 1821.

SIMONI, Luís Vicente de.

Plano das dietas diárias que dar-se-ão aos Doentes no Hospital Real Militar da cidade de Moçambique. Ilha de Moçambique. Fundo do Século XIX, códice 11.4780 Gd6, fl.203-203v. (Arquivo Histórico de Moçambique, Maputo). 1 jan. 1820.

SMITH, Ginnie.

Prescribing the rules of health: self-help and advice in the late eighteenth century. In:

Porter, Roy (Ed.). Patients and practitioners: lay perceptions of medicine in pre-industrial society. Cambridge: Cambridge University Press. p.249282. 2002.

SOUSA, Germano de.

História da medicina portuguesa durante a expansão. Lisboa: Temas e Debates; Círculo de Leitores. 2013.

SPARY, E.C.

Eating the enlightenment: food and the sciences in Paris, 1670-1760. Chicago: The University of Chicago Press. 2012.

VIGARELLO, Georges.

As metamorfoses do gordo: história da obesidade. Petrópolis: Vozes. 2012. 